\title{
COMPOSITION AND ORIGIN OF SUMMERTIME AIR POLLUTANTS AT DEEP CREEK LAKE, MARYLAND
}

\author{
Teri L. Vossler*, Charles W. Lewis $\dagger$, Robert K. Stevens and Thomas G. Dzubay \\ Atmospheric Research and Exposure Assessment Laboratory, U.S. Environmental Protection Agency, \\ Research Triangle Park, NC 27711, U.S.A. \\ Glen E. Gordon and Semra G. Tuncel \\ Department of Chemistry, University of Maryiand, College Park, MD 20742, U.S.A.
}

George M. RusSWURM

Northrop Services, Inc., Research Triangle Park, NC 27709, U.S.A.

and

\author{
Gerald J. KeEler § \\ Department of Atmospheric and Oceanic Science, University of Michigan, Ann Arbor, MI 48109, U.S.A.
}

(First received 23 September 1988 and in final form 19 December 1988)

\begin{abstract}
A 1 month intensive summertime field study conducted in rural western Maryland resulted in a comprehensive set of fine particle, gaseous and meteorological data. Sulfur in the assumed form of ammonium sulfate accounted for $67 \%$ of the average fine particle mass and had a very high correlation with fine particle mass $(r=0.99)$. Other measured species, including carbon and nitrate, made only minor contributions to the fine mass. Peak sulfate concentrations, averaged over $6-\mathrm{h}$ intervals, exceeded $50 \mu \mathrm{g} \mathrm{m}^{-3}$. Nitric acid concentrations showed strong daytime maxima and on a $24 \mathrm{~h}$ basis were about four times those of fine particle nitrate. Sulfur in the gas phase $\left(\mathrm{SO}_{2}\right)$ constituted more than half of the total sulfur, indicating that the sampling site was being influenced by local sources. Fine particle selenium was well correlated with fine particle sulfur $(r=0.70)$. The ratio of fine particle sulfur to selenium was 2800 , characteristic of a rural site downwind of coal-burning areas. Mixed-layer back trajectories were used to identify possible source regions for the measured parameters. Wind frequency-normalized concentrations of parameters associated with coal-burning $\left(\mathrm{S}, \mathrm{Se}, \mathrm{SO}_{2}\right.$ and mass) were highest for back trajectories arriving at Deep Creek Lake from the west-northwest. Use of Rahn and Lowenthal regional signatures showed an overwhelming dominance by the Lower Midwest region, and a surprisingly weak impact by the Upper Midwest region, at the site.
\end{abstract}

Key word index: Fine particles, sulfur, $\mathrm{SO}_{2}$, nitric acid and nitrate, mixed-layer back trajectory, regional signatures.

\section{INTRODUCTION}

In August of 1983 a comprehensive field study was conducted under the name of the Deep Creek Lake (DCL) field study. The DCL study was part of a larger one involving many participants in which coordinated measurements were performed at three ground level sites, one being near Deep Creek Lake in western Maryland, operated by the EPA, and the others being Laurel Hill and Allegheny Mountain in southwestern

\footnotetext{
- National Research Council Resident Research Associate Present address: Geophysics Laboratory, Hanscom Air Force Base, MA 01731, U.S.A.

† Author to whom correspondence should be addressed.

$\$$ Present address: Department of Chemistry, Middle East Technical University, Ankara, Turkey.

\$Present address: Harvard School of Public Health, 665 Huntington Avenue, Boston, MA 02115, U.S.A.
}

Pennsylvania, operated by Ford Research Laboratory (Pierson et al., 1987, 1989). In addition to ground-level ambient measurements, stack sampling was performed at selected local coal-fired power plants and airborne sampling was performed in the power plant plumes. The overall objective of the EPA-supported phase of the field study was to test the feasibility of using regional-scale receptor modeling to determine the impacts of primary and secondary pollutants from coal-fired power plants on ambient air quality. The selection of the DCL site was made with this objective in mind. The DCL site, located on the campus of Garrett Community College in a primarily rural area, was expected to be strongly impacted by coal-fired power plants located within $100 \mathrm{~km}$ of the sampling site as well as by coal-burning facilities further to the west in the Ohio Valley region (Fig. 1).

The principal features of the DCL data set are (1) the relatively long duration ( 1 month) of the study, 


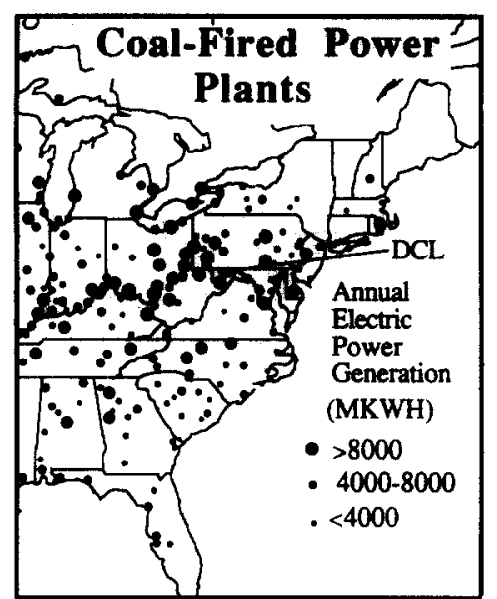

Fig. 1. Coal-fired power plants in eastern U.S.A.

(2) the short time resolution (6-h) of the measurements, (3) the unusually complete chemical characterization of the aerosol and gases, (4) the availability of a complete set of back trajectories with 6-h time resolution, and (5) accompanying measurements of three upwind power plants both in-plume and in-stack. It is the combination of these characteristics that makes the DCL data set unusually attractive.

The present paper serves as an introduction to the ambient results obtained at DCL for fine particles and concurrent gas and meteorological measurements. The overall objective of determining the primary and secondary impact of coal-burning sources using receptor modeling techniques will be addressed in greater detail in papers to follow, as source profile data become available.

\section{EXPERIMENTAL}

The data presented in this paper were obtained over the period 1-31 August 1983 at the DCL site $\left(39^{\circ} 34^{\prime} \mathrm{N}, 79^{\circ} 20 \mathrm{~W}\right)$. Particulate samples were collected for four 6-h periods each day beginning at $0400,1000,1600$ and 2200 EDT. Gaseous species and meteorological parameters were monitored continuously.

Fine and coarse particle samples were collected with a Lawrence Berkeley Laboratory (LBL) dichotomous sampler (Loo et al., 1976) and a Beckman dichotomous sampler having nominal fow rates of 50 and $16.7 / \mathrm{min}^{-1}$, respectively. Both samplers had a cutpoint of $2.5 \mu \mathrm{m}$ to separate coarse and fine particles and collect them on $37-\mathrm{mm}$ dia. $2-\mu \mathrm{m}$ pore size Teflon filters. Although both coarse and fine particle samples were available, only the fine particle data are presented here. Analyses by $\beta$-ray attenuation for mass (Courtney et al., 1982) and by X-ray fluoresonce (XRF) for elemental composition (Dasbay et al., 1982) were performed at the Atmospheric Research and Exposure Alecasment Laboratory on filters collected with the LBL sampler. Inatrumentul neutron activation analysis (INAA) was porformed at the National Bureau of Standande (NBS) research reactor. Only ono-thind of the INAA samples were from the LBL sampler, with the remainder from the Bectoman ampler.

Species measured continuoully were $\mathrm{SO}_{2}, \mathrm{O}_{3}, \mathrm{NO}$. $\mathrm{NO}_{2}$ and $\mathrm{NO}_{x}$, as well as light scattering tempernture, dewpoint and solar insolation. Sulfur dioxide was measured with a
TECO model 43 pulsed u.v. fluorescence analyzer with a rated accuracy the larger of $2 \mathrm{ppb}$ or $10 \% ; \mathrm{O}_{3}$ was measured with a Bendix model 8002 chemiluminescence analyzer with a rated accuracy the larger of $1 \mathrm{ppb}$ or $10 \% ; \mathrm{NO}, \mathrm{NO}_{2}$ and $\mathrm{NO}_{x}$ were measured with a Bendix model $8101-\mathrm{B}$ chemiluminescence analyzer with a rated accuracy the larger of $5 \mathrm{ppb}$ or $10 \%$. Accuracies for the gas monitoring devices were verified by three multipoint calibrations performed over the course of the study. Zero and span calibrations were made at least every other day. Light scattering, represented by bsph, was monitored with an MRI model 1561 integrating nephelometer with $10 \%$ accuracy. Air passing through the nephelometer was heated approximately $10^{\circ} \mathrm{C}$ to reduce relative humidity effects. The instrument was calibrated with Freon12 three times during the study, and precision checks were performed twice daily. Temperature and dew point were monitored with a Climatronics sensor model 100325-2 with $\pm 2^{\circ} \mathrm{C}$ accuracy. Solar insolation was monitored with an Eppley pyranometer model 2; an accuracy $<5 \%$ was inferred from comparisons of the device with standards performed at NBS over the preceding several years. Continuously monitored data were first averaged over $1-h$ intervals, deleting $1-h$ intervals which included calibrations. The remaining 1 -h data were then averaged over the 6-h intervals corresponding to the sampling schedule of the dichotomous samplers.

The denuder difference method (Shaw et al., 1982) was employed to measure separately nitric acid and particulate nitrate. Ambient air passed through a Teflon cyclone at about $30 \ell \mathrm{min}^{-1}$ to remove particles larger than $2.5 \mu \mathrm{m}$. Portions of the airstream subsequently passed through parallel denuding and non-denuding legs and finally to the corresponding nylon filters (Membrana $1-\mu \mathrm{m}$ pore size). Flow through each leg was limited to about $3 \ell \mathrm{min}^{-1}$ by critical orifices. The daily sampling schedule for the denuder difference apparatus included one 6-h daytime sample starting at 1000 EDT and one 18-h sample starting at 1600 EDT. The denuder difference nylon filter samples were extracted and analyzed for nitrate by ion chromatography at EPA by Northrop Services, Inc.

Fine particle samples for carbon analysis were collected on quartz filters (Pallfex type 2500 QAST) with a modified Sierra dichotomous sampler (Stevens, 1986) at an average flow rate of $26 \pm 1 \ell \mathrm{min}^{-1}$. These samples were sent to Sunset Laboratory in Forest Grove, Oregon for the analysis of elemental carbon (CEL) and volatilizable carbon (CVOL) by a thermal-optical method, similar to that of Johnson et al. (1981)

\section{RESULTS AND DISCUSSION}

\section{Diurnal averages}

Parameter averages at DCL are presented in Table 1. Averages are given for all samples as well as for daytime (1000-2200 EDT) and night-time (2200-1000 EDT) sampling intervals. In general only those parameters with average uncertainties $\leqslant 30 \%$ were included in this summary. Exceptions were NO, $\mathrm{NO}_{2}$ and $\mathrm{NO}_{x}$, which were measured near their detection limits. Usually the uncertainty given in the last column is the average standard deviation for a single measurement divided by the 'all cases' mean. For the calculated ratios $S / S e$ and $S_{a} / S_{p}$, however, the uncertainty is the coefficient of variation for 'all cases'. Most of the averages are based on a common set of 98 cases having no missing values, out of 120 possible cases. The carbon averages (CEL and CVOL) are based on 97 cases, but about $20 \%$ of the cases are not 
Table 1. Fine particle, gas and meteorological parameter averages measured at Deep Creek Lake during August 1983

\begin{tabular}{|c|c|c|c|c|c|c|c|c|c|}
\hline \multirow[b]{2}{*}{ Parameter* } & \multirow[b]{2}{*}{ Method } & \multirow[b]{2}{*}{ Units } & \multicolumn{2}{|c|}{ All } & \multicolumn{2}{|c|}{ Day } & \multicolumn{2}{|c|}{ Night } & \multirow[b]{2}{*}{ Uncertainty } \\
\hline & & & $\begin{array}{l}\text { No. } \\
\text { cases }\end{array}$ & Mean & $\begin{array}{l}\text { No. } \\
\text { cases }\end{array}$ & Mean & $\begin{array}{l}\text { No. } \\
\text { cases }\end{array}$ & Mean & \\
\hline Mass & BETA & $\mathrm{ng} \mathrm{m}^{-3}$ & 98 & 40,000 & 51 & 47,000 & 47 & 32,000 & $7 \%$ \\
\hline CEL & THERM & $\mathrm{ng} \mathrm{m} \mathrm{m}^{-3}$ & 97 & 180 & 51 & 160 & 46 & 190 & $24 \%$ \\
\hline CVOL & THERM & $n g m^{-3}$ & 97 & 1450 & 51 & 1390 & 46 & 1520 & $7 \%$ \\
\hline $\mathrm{NO}_{3}^{-}$ & DDM & $n g m^{-3}$ & 59 & 570 & 29 & 650 & 30 & 500 & $20 \%$ \\
\hline $\mathrm{HNO}_{3}$ & DDM & $\mathrm{ng} \mathrm{m} \mathrm{m}^{-3}$ & 59 & 2500 & 29 & 4100 & 30 & 1100 & $30 \%$ \\
\hline $\mathrm{Na}$ & INAA & $n g \mathrm{~m}^{-3}$ & 98 & 34 & 51 & 36 & 47 & 33 & $19 \%$ \\
\hline $\mathbf{S i}$ & XRF & $n g \mathrm{~m}^{-3}$ & 98 & 150 & 51 & 170 & 47 & 130 & $23 \%$ \\
\hline$S$ & XRF & $\mathrm{ng} \mathrm{m} \mathrm{m}^{-3}$ & 98 & 6700 & 51 & 7800 & 47 & 5500 & $9 \%$ \\
\hline K & XRF & $\mathrm{ng} \mathrm{m^{-3 }}$ & 98 & 44 & 51 & 46 & 47 & 42 & $11 \%$ \\
\hline $\mathrm{Ca}$ & XRF & $\mathrm{ng} \mathrm{m} \mathrm{m}^{-3}$ & 98 & 48 & 51 & 57 & 47 & 39 & $11 \%$ \\
\hline Sc & INAA & $\mathrm{ng} \mathrm{m} \mathrm{m}^{-3}$ & 98 & 0.013 & 51 & 0.015 & 47 & 0.010 & $23 \%$ \\
\hline V & INAA & $\mathrm{ng} \mathrm{m}^{-3}$ & 98 & 0.81 & 51 & 0.91 & 47 & 0.71 & $11 \%$ \\
\hline $\mathbf{M n}$ & INAA & $\mathrm{ng} \mathrm{m}^{-3}$ & 98 & 3.2 & 51 & 3.2 & 47 & 3.1 & $8 \%$ \\
\hline $\mathrm{Fe}$ & XRF & $n g m^{-3}$ & 98 & 58 & 51 & 60 & 47 & 55 & $9 \%$ \\
\hline $7 . n$ & XRF & $n \mathrm{~g} \mathrm{~m}^{-3}$ & 98 & 13 & 51 & 12 & 47 & 13 & $12 \%$ \\
\hline As & INAA & $\mathrm{ng} \mathrm{m}^{-3}$ & 98 & 0.80 & 51 & 0.79 & 47 & 0.80 & $9 \%$ \\
\hline $\mathrm{Se}$ & INAA & $n g \mathrm{~m}^{-3}$ & 98 & 2.5 & 51 & 2.5 & 47 & 2.5 & $7 \%$ \\
\hline $\mathrm{Br}$ & XRF & $n g m^{-3}$ & 98 & 5.3 & 51 & 4.8 & 47 & 5.9 & $14 \%$ \\
\hline $\mathrm{Sb}$ & INAA & $\mathrm{ng} \mathrm{m} \mathrm{m}^{-3}$ & 98 & 0.66 & 51 & 0.50 & 47 & 0.83 & $17 \%$ \\
\hline $\mathrm{La}$ & INAA & $\mathrm{ng} \mathrm{m} \mathrm{m}^{-3}$ & 98 & 0.08 & 51 & 0.09 & 47 & 0.07 & $23 \%$ \\
\hline $\mathrm{Pb}$ & XRF & $\mathrm{ng} \mathrm{m} \mathrm{m}^{-3}$ & 98 & 48 & 51 & 46 & 47 & 50 & $9 \%$ \\
\hline $\mathrm{SO}_{2}$ & CONT & $\mathrm{ppb}$ & 98 & 8 & 51 & 10 & 47 & 5 & $2 \mathrm{ppb}$ \\
\hline $\mathrm{NO}_{x}$ & CONT & $\mathrm{ppb}$ & 98 & 5.1 & 51 & 4.0 & 47 & 6.4 & $5 \mathrm{ppb}$ \\
\hline NO & CONT & $\mathrm{ppb}$ & 98 & 1.2 & 51 & 0.3 & 47 & 2.1 & $5 \mathrm{ppb}$ \\
\hline $\mathrm{NO}_{2}$ & CONT & $\mathrm{ppb}$ & 98 & 4.0 & 51 & 3.8 & 47 & 4.3 & $5 \mathrm{ppb}$ \\
\hline $\mathrm{O}_{3}$ & CONT & $\mathrm{ppb}$ & 84 & 48 & 44 & 61 & 40 & 34 & $10 \%$ \\
\hline bsph & CONT & $\mathrm{m}^{-1} 10^{4}$ & 98 & 1.2 & 51 & 1.4 & 47 & 1.0 & $10 \%$ \\
\hline SRAD & CONT & $W m^{-2}$ & 98 & 260 & 51 & 410 & 47 & 90 & $5 \%$ \\
\hline WSPD & TRAJ & $\mathrm{km} \mathrm{h}^{-1}$ & 93 & 18 & 49 & 18 & 44 & 18 & $25 \%$ \\
\hline RHUM & CALC & $\%$ & 97 & 64 & 51 & 57 & 46 & 72 & $10 \%$ \\
\hline TEMP & CONT & ${ }^{\circ} \mathrm{C}$ & 98 & 19 & 51 & 22 & 47 & 16 & $2^{\circ} \mathrm{C}$ \\
\hline $\mathbf{S} / \mathbf{S e}$ & CALC & None & 97 & 2800 & 51 & 3400 & 46 & 2100 & $54 \%$ \\
\hline$S_{g} / S_{p}$ & CALC & None & 98 & 1.5 & 51 & 1.5 & 47 & 1.4 & $88 \%$ \\
\hline
\end{tabular}

* Mass = fine particle mass; $\mathrm{CEL}=$ elemental carbon; $\mathrm{CVOL}=$ volatilizable carbon; $\mathrm{NO}_{3}^{-}=$particulate nitrate; bsph $=$light scattering coefficient from heated nephelometer; $S R A D=$ solar radiation; $W S P D=$ wind speed; $R H U M=$ relative humidity; TEMP = temperature; $S_{\mathrm{q}}=$ gaseous sulfur; $S_{p}=S=$ particulate sulfur.

$\mathrm{XRF}=\mathrm{X}$-ray fluorescence; INAA $=$ instrumental neutron activation analysis; $\mathrm{BETA}=\beta$-gauge method; THERM $=$ thermal-optical technique; CONT = continuous monitoring instrument; DDM=denuder difference method; TRAJ $=$ mixed-layer back trajectories; CALC $=$ calculated from above data.

Day is $1000-2200$ EDT.

Night is 2200-1000 EDT.

common to the 98 case set. The number of cases shown for $\mathrm{HNO}_{3}$ and $\mathrm{NO}_{3}^{-}$is deceptive as only two samples per day were available, one being an 18-h sample.

Table 1 shows that $\mathrm{S}$ was the dominant fine particulate species and, when expressed as $\mathrm{SO}_{4}^{2-}$ ion, constituted $49 \%$ of the average fine particle mass. The percentage increases to $67 \%$ if the $S$ were in the form of $\left(\mathrm{NH}_{4}\right)_{2} \mathrm{SO}_{4}$ at the time of analysis, which was likely the case since no precautions were taken to preserve the acidity of the original sample. Both $\mathrm{S}$ and $\mathrm{SO}_{2}$ were higher during the day than at night.

$\mathrm{The} \mathrm{Br} / \mathrm{Pb}$ ratio, typically found in the range $0.3-0.4$ in urban areas (Lewis et al., 1987; Koutrakis and Spengler, 1987), consistent with a motor vehicle origin, was 0.11 for all $\mathrm{DCL}$ samples. Since the $\mathrm{Pb}-\mathrm{Br}$ correlation coefficient was 0.80 , a predominantly motor vehicle origin is still likely, but the low $\mathrm{Br} / \mathrm{Pb}$ ratio found at DCL is indicative of an acidic aerosol, which can displace bromine. In fact electron microscopic measurements (Mamane and Dzubay, 1986) on DCL aerosol samples showed a large contribution from acidic sulfates. In addition high aerosol acidities were frequently measured concurrently at the two sites operated by Ford Research Laboratory (Pierson et al., 1989).

The ratios of gaseous to particulate nitrate, $\mathrm{HNO}_{3} / \mathrm{NO}_{3}^{-}$, were about $6: 1$ for the 6-h daytime periods and $2: 1$ for the 18 -h 'night-time' periods. Samples confined strictly to hours of darkness presumably would have shown an even smaller $\mathrm{HNO}_{3} / \mathrm{NO}_{3}^{-}$ratio. Table 1 shows that particulate $\mathrm{NO}_{3}^{-}$concentrations were rather constant, so that most of the diurnal variation in the ratio is due to $\mathrm{HNO}_{3}$ changes. Such a diurnal variation of $\mathrm{HNO}_{3}$ is 
consistent with photochemical formation of its precursors during daytime and rapid depletion, largely by dry deposition, during night-time.

CEL and CVOL together constituted a small fraction of the total fine particle mass, averaging only $4 \%$. The percentage would increase to no more than $5 \%$ if the $\mathrm{H}$ and $\mathrm{O}$ associated with $\mathrm{CVOL}$ were included (Countess et al., 1980; Shah et al., 1984). Particulate $\mathrm{NO}_{3}^{-}$and its associated cation (probably $\mathrm{NH}_{4}^{+}$) was the next most important contributor to fine particle mass, yet accounted for only $2 \%$ of the fine particle mass. All other measured fine particle species were negligible contributors.

The average $\mathrm{S} / \mathrm{Se}$ ratio was $2800 \pm 1500$ (mean \pm std dev) for all samples. This agrees with the 3000 ratio found by Tuncel et al. (1985) for rural sites well downwind of coal-burning areas. The average ratio of gaseous to particulate sulfur, $S_{z} / S_{p}$, shows more than half of the total sulfur (as $S$ ) was present in the gaseous state, indicating the presence of local sources.

Analysis of samples by INAA provided concentrations of many elements in addition to those measured by XRF. Particular elements that are measured reasonably well by either method provide a means of quality assurance for the two methods. Ratios of concentrations of five such elements measured for the same sampling intervals by XRF and INAA are presented in Table 2. Even though most XRF and INAA samples were not physically the same filter, the ratios are generally consistent with unity within their uncertainties. The best agreements are for $\mathrm{Fe}$ and $\mathrm{Zn}$, which also have the smallest uncertainties. For each element either the XRF or INAA measurement results were chosen according to which method had the smaller analytical error. It should be remembered that the XRF samples were on average more heavily loaded and thus analytically more favorable, since they were obtained at $50 \ell \mathrm{min}^{-1}$, while two-thirds of the INAA samples were from $16.7 \ell \mathrm{min}^{-1}$ sampling.

\section{Temporal variations of key parameters}

Figure 2 shows the temporal variation of some closely associated species. Fine particle concentrations of mass (Fig. 2a) and S (Fig. 2b) tracked each other remarkably well. This is a consequence of the fact that up to $67 \%$ of the fine particle mass was $\mathrm{SO}_{4}^{2-}$ and related cations, as detailed above. The remarkable

Table 2. Ratios of XRF/INAA concentrations for the DCL fine particle samples

\begin{tabular}{lcc}
\hline Parameter & No. cases & $\begin{array}{c}\text { Ratio of means } \\
\text { XRF/INAA }\end{array}$ \\
\hline $\mathrm{S}$ & 98 & $1.34 \pm 0.31$ \\
$\mathrm{Fe}$ & 98 & $0.87 \pm 0.18$ \\
$\mathrm{Zn}$ & 98 & $0.98 \pm 0.18$ \\
$\mathrm{Se}$ & 106 & $1.32 \pm 0.24$ \\
$\mathrm{Br}$ & 98 & $1.33 \pm 0.41$ \\
\hline
\end{tabular}

similarity of these two parameters also serves an important quality assurance role since the underlying analytical procedures ( $\beta$-ray attenuation and XRF) are quite different. Selenium, thought to be a possible tracer for coal-fired power plants, tracked $S$ fairly well (Fig. 2c). For contrast $\mathrm{Pb}$ was also included in this comparison since it is a common well-measured element, but is not expected to dominate fine particles or behave the same as elements whose primary source is coal combustion. Indeed, the $\mathrm{Pb}$ variation (Fig. 2d) has very little similarity to the others. A striking feature of these figures is the very high concentrations (e.g. $>50 \mu \mathrm{g} \mathrm{m}^{-3}$ for $\mathrm{S}$ expressed as $\mathrm{SO}_{4}^{2-}$ ) attained during peak periods, which is emphasized by the short sampling periods.

\section{Wind directional dependence of parameters}

The behavior of measured and calculated parameters with respect to wind direction was examined with mixed-layer back trajectories calculated using the ARL-ATAD model (Heffter, 1980). The trajectories represent the most probable path of an air parcel advected with the mixed layer-averaged winds. A back trajectory is useful for establishing the direction of arrival of a pollutant species, but does not of itself give any information on the distance to the source in that direction. Trajectories were calculated by the method of Samson (1980) starting at the sampling site and moving backwards in time in 3-h increments using available National Weather Service upper-air observations. Mixed-layer trajectories such as that shown in Fig. 3 were calculated for air arriving at DCL at 0200 , 0800,1400 and $2000 \mathrm{EDT}$, roughly corresponding to the midpoints of the sampling periods, for the entire study. With DCL at the center, the area was divided into eight equal sectors as shown in Fig. 4. Using the last $24 \mathrm{~h}$ of each trajectory the average wind sector frequency distribution, $\left[F_{j}\right]$, was calculated via

$$
\left[F_{j}\right]=\sum P_{i j} / N
$$

where $P_{i j}$ is the fraction of the 24-h trajectory lying in wind sector $j$ for sampling period $i$, and $N$ is the number of sampling periods. The results of Equation (1) are shown in the first line of Table 3 . Three of the wind sectors (ESE, SSE and SSW) occurred with insignificant $(<3 \%)$ frequency and were not included in the table.

The choice of $24 \mathrm{~h}$ represented a compromise between the desirability of identifying potential sources as distant as possible and the increasing lack of definition of an extended trajectory. Twenty four hours was also a practical choice since it was the longest duration for which back trajectories were available for virtually every sampling period. For an average wind speed of $18 \mathrm{~km} \mathrm{~h}^{-1}$ (Table 1), $24 \mathrm{~h}$ is equivalent to more than $400 \mathrm{~km}$.

The average fractional contribution to parameter $k$ from each wind sector $j$ is also given in Table 3, as 
calculated from

$$
\left[C_{k j}\right] /\left[C_{k}\right]=\frac{1}{N} \sum\left(C_{i k} \star P_{i j}\right) /\left[C_{k}\right]
$$

For an alternative comparison, the mean values of each parameter in each wind sector were normalized with respect to wind sector frequency, as given by

$$
\text { normalized }\left[C_{k j}\right]=\left[C_{k j}\right] /\left[F_{j}\right] \text {. }
$$

The normalization step insures that there is no bias toward any wind sector because of its frequency of occurrence. In other words, the calculation gives the average concentrations seen when the wind is only from the indicated wind sector, effectively a "wind sector source profile'. This procedure is similar to that used by Parekh and Husain (1982).

Wind frequency-normalized values of important parameters are plotted in Fig. 5 for each of the five important wind sectors. Parameters have been grouped together if the highest normalized concentration for each occurs in the same wind sector. For example Sc, $\mathrm{V}$ and As are grouped because their
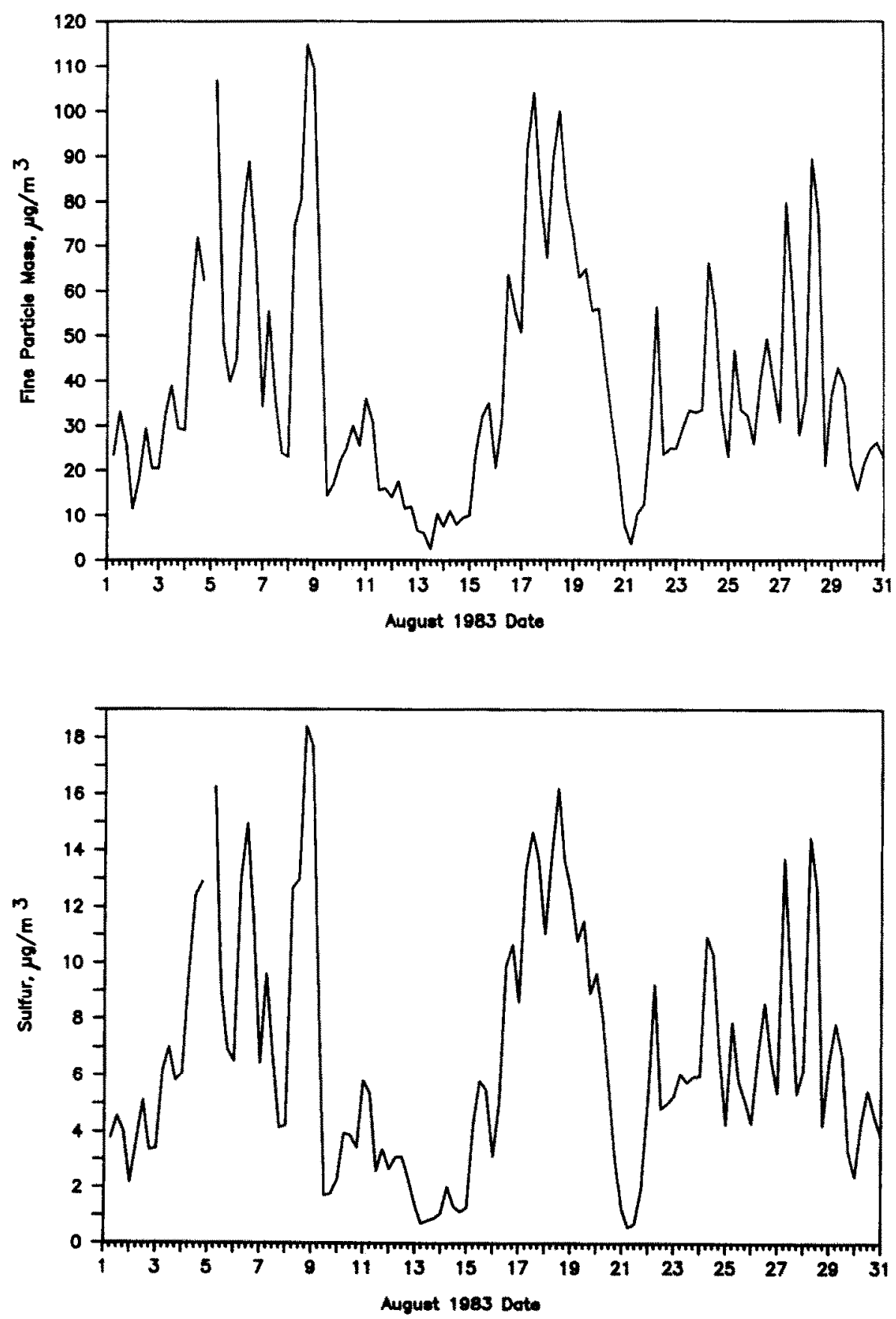

Fig. 2(a,b). 

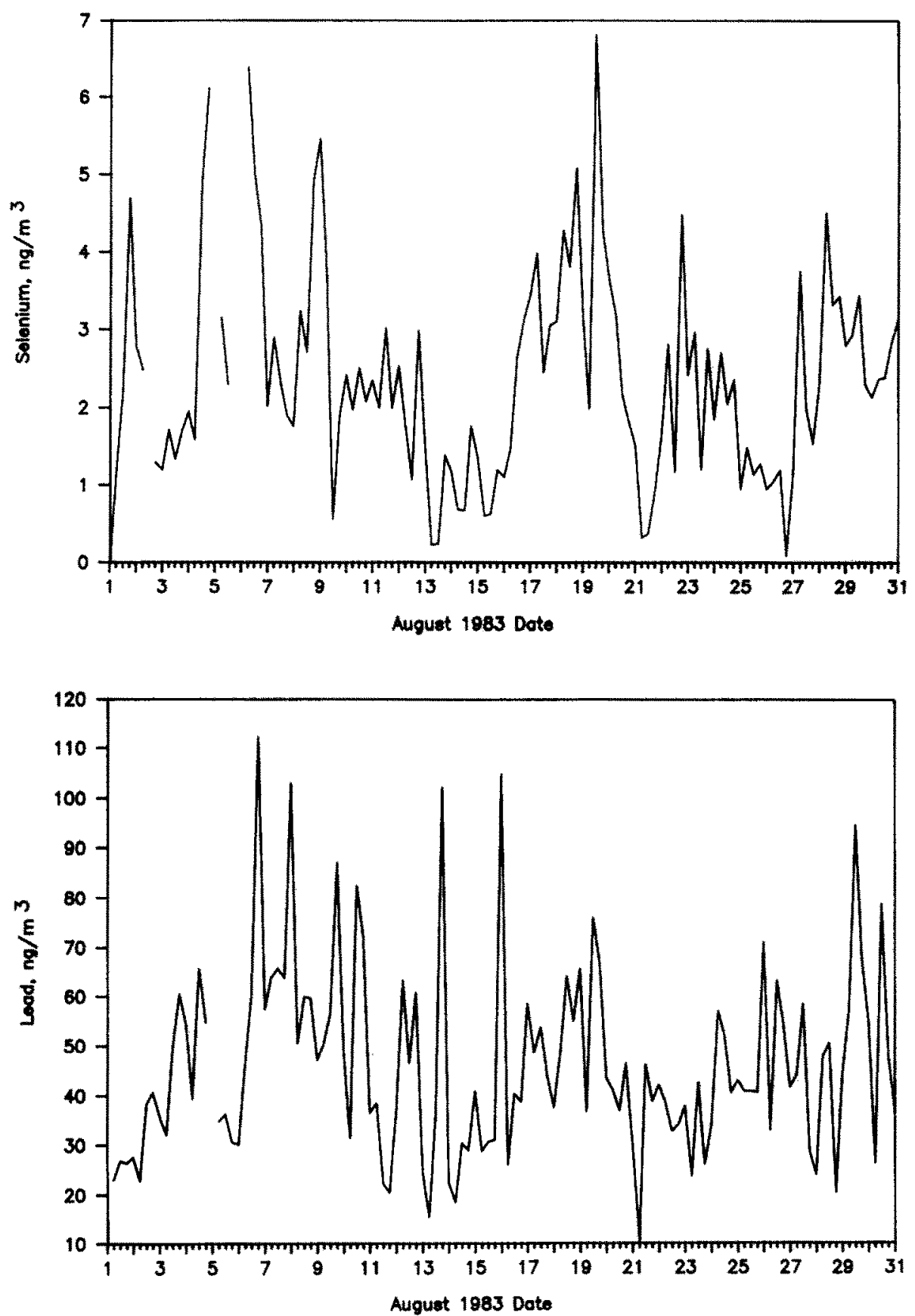

Fig. 2. Concentrations of (a) fine particle mass, (b) sulfur, (c) selenium and (d) lead as functions of the sampling interval indicated by each tick matk on the $x$-axis.

highest concentrations all occur in the ENE sector. The association of high $V$ loadings with ENE is expected, because of the dominance of oil-burning power plants in the eastern and northeastern U.S.

Less expected were the higher concentrations of soil-related elements ( $\mathrm{Ca}, \mathrm{Fe}$ and $\mathrm{Si}$ ) associated with the WSW sector. Tuncel et al. (1985) also observed that the concentrations of $\mathrm{Al}$ and $\mathrm{Si}$ at the EPA Shenandoah Valley sampling site $(130 \mathrm{~km}$ southsoutheast of DCL) were highest for southwest trajectories.
Normalized values of parameters associated with coal-burning power plants ( $\mathrm{S}, \mathrm{Se}, \mathrm{SO}_{2}$, mass and bsph) were highest for WNW trajectories. Figure 1 clearly shows the greatest concentration of coal-fired power plants to be in the NNW-WNW-WSW directions. The ratio $S_{g} / S_{p}$ is largest for the $W N W$ and $N N W$ wind sectors, indicating a grenter relative impact of local vs distant $\mathrm{SO}_{2}$ sources in the northwest quadrant.

Normalized concentrations of elements related to other anthropogenic activity ( $\mathrm{Mn}, \mathrm{Zn}, \mathrm{Br}$ and $\mathrm{Pb}$ ) 


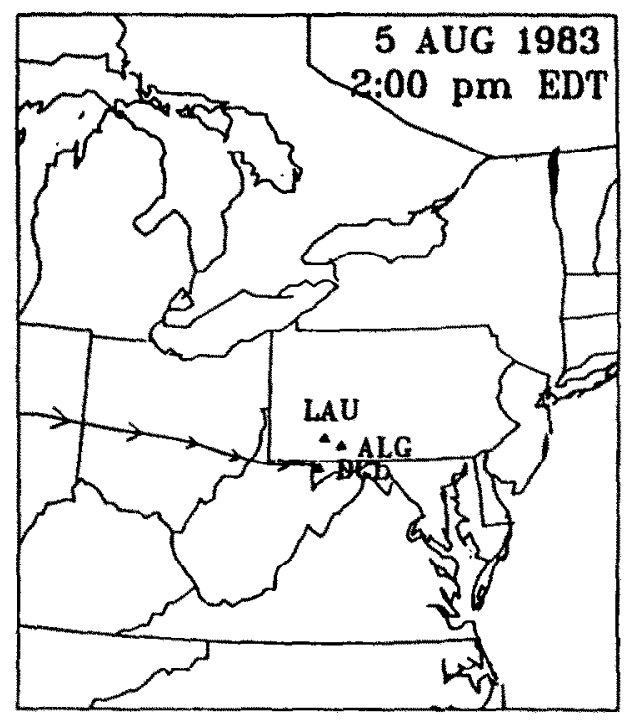

Fig. 3. Mixed-layer back trajectory example. Sampling sites at Deep Creek Lake (DCL), Allegheny Mountain (ALG) and Laurel Hill (LAU) are shown.
Table 3. Per cent contribution to average parameter value for five wind sectors

\begin{tabular}{lrrrrr}
\hline Parameter & ENE & NNE & NNW & WNW & WSW \\
\hline Wind frequency & 6 & 16 & 29 & 28 & 21 \\
Mass & 4 & 7 & 28 & 37 & 24 \\
CEL & 6 & 12 & 28 & 26 & 24 \\
CVOL & 5 & 11 & 30 & 30 & 21 \\
NO $_{3}^{-}$ & 5 & 11 & 28 & 27 & 25 \\
$\mathrm{HNO}_{3}$ & 5 & 8 & 36 & 28 & 20 \\
$\mathrm{Na}$ & 7 & 14 & 25 & 30 & 24 \\
$\mathrm{Si}$ & 3 & 13 & 26 & 32 & 27 \\
$\mathrm{~S}$ & 4 & 7 & 28 & 38 & 24 \\
$\mathrm{~K}$ & 4 & 12 & 31 & 31 & 22 \\
$\mathrm{Ca}$ & 5 & 16 & 26 & 28 & 25 \\
$\mathrm{Sc}$ & 9 & 14 & 27 & 28 & 23 \\
$\mathrm{~V}$ & 10 & 25 & 26 & 23 & 16 \\
$\mathrm{Mn}$ & 2 & 12 & 38 & 31 & 17 \\
$\mathrm{Fe}$ & 3 & 11 & 34 & 30 & 22 \\
$\mathrm{Zn}$ & 3 & 9 & 42 & 29 & 17 \\
$\mathrm{As}$ & 9 & 17 & 40 & 22 & 13 \\
$\mathrm{Se}$ & 3 & 10 & 32 & 34 & 21 \\
$\mathrm{Br}$ & 4 & 16 & 30 & 27 & 22 \\
$\mathrm{Sb}$ & 5 & 10 & 30 & 29 & 27 \\
$\mathrm{La}$ & 3 & 11 & 21 & 34 & 31 \\
$\mathrm{~Pb}$ & 4 & 14 & 34 & 28 & 20 \\
$\mathrm{SO}$ & 3 & 6 & 31 & 43 & 17 \\
bsph & 3 & 7 & 28 & 38 & 24 \\
\hline
\end{tabular}

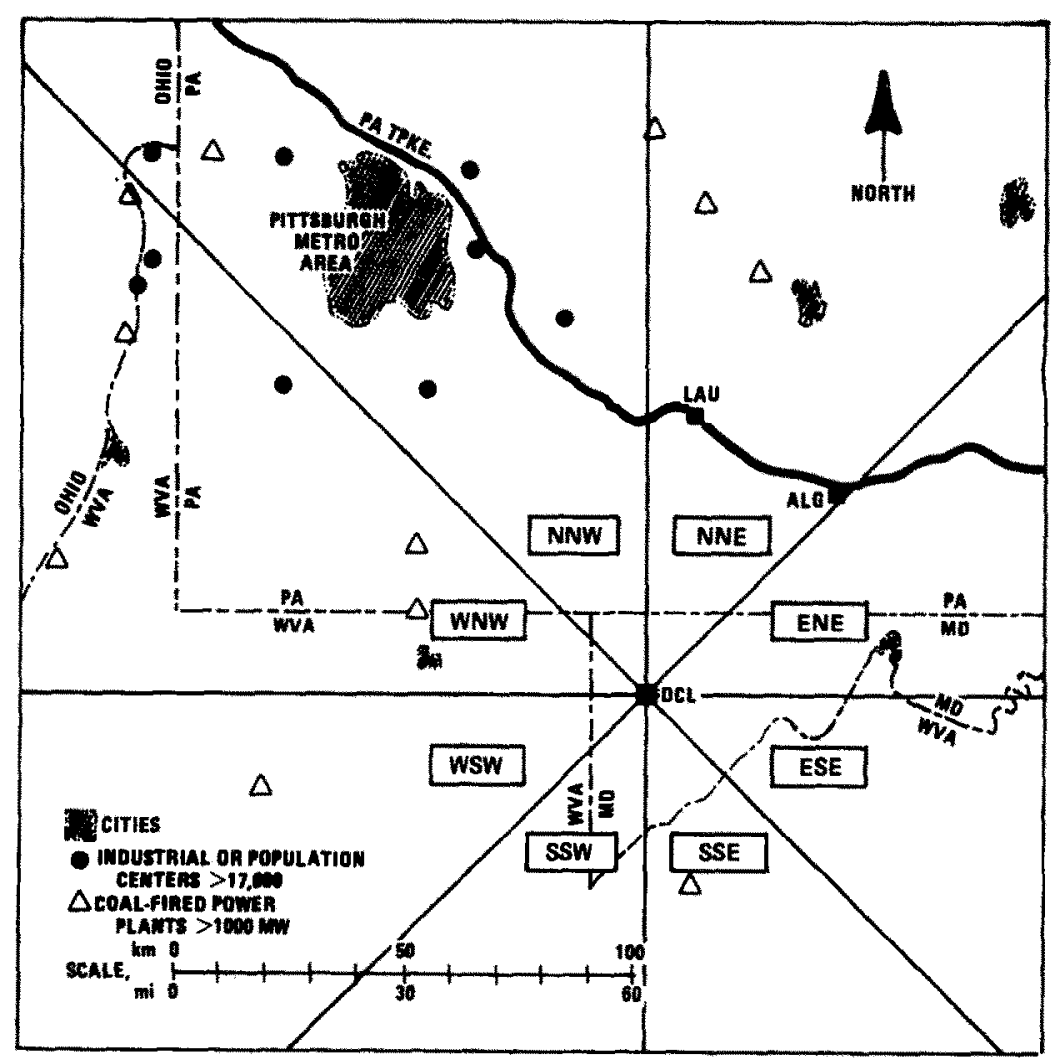

Fig. 4. Wind sector identification. 

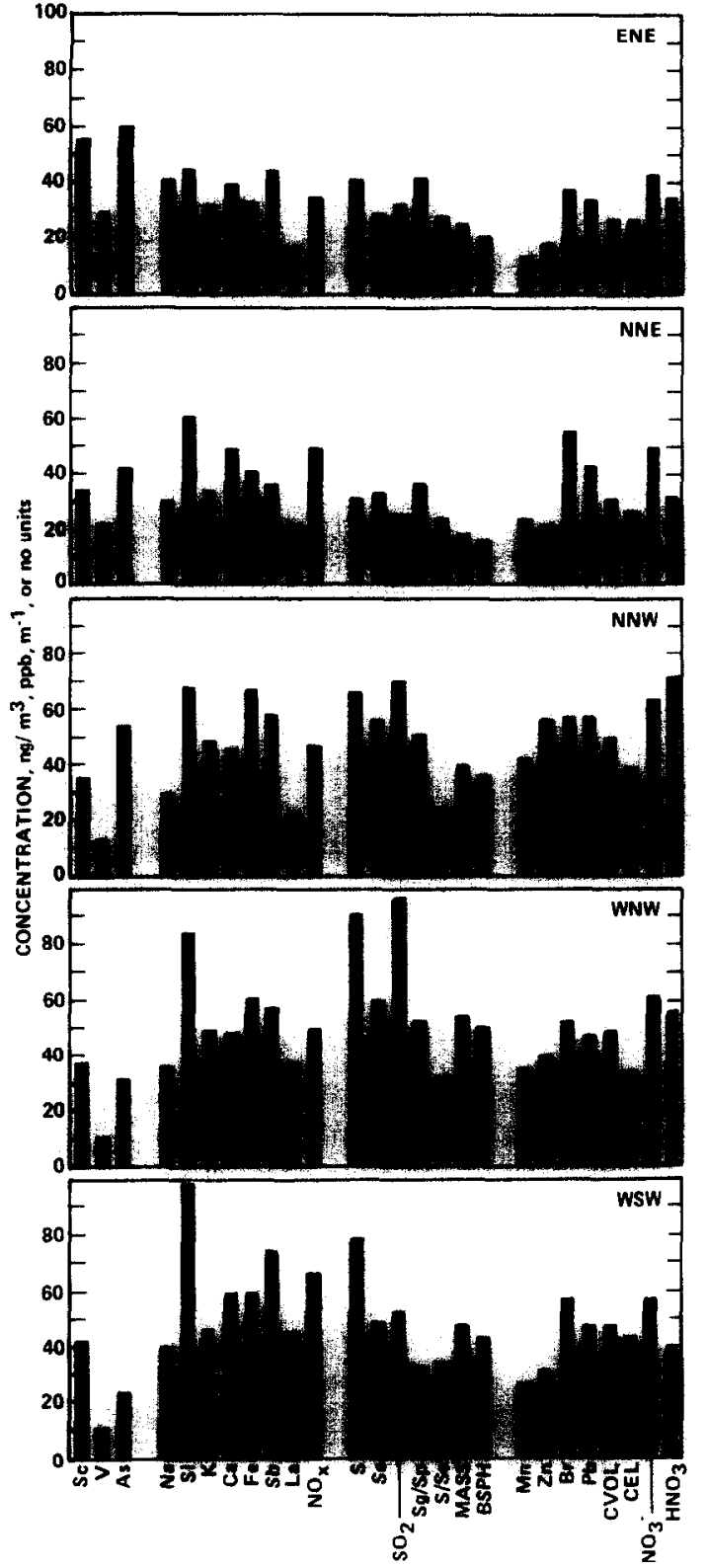

Fig. 5. Average wind frequency-normalized concentrations of parameters for five wind sectors observed at DCL. Concentrations were multiplied by the following scale factors: $\mathrm{Sc}(3000), \mathrm{V}(20), \mathrm{As}(50), \mathrm{Na}(1), \mathrm{Si}(0.5), \mathrm{K}(1), \mathrm{Ca}(1)$, $\mathrm{Fe}(1), \mathrm{Sb}(100), \mathrm{La}(400), \mathrm{NO}_{x}(10), \mathrm{S}(0.01), \mathrm{Se}(20), \mathrm{SO}_{2}(8)$, $\mathrm{S}_{\mathrm{g}} / \mathrm{S}_{\mathrm{p}}(30), \mathrm{S} / \mathrm{Se}(0.01)$, MASS (0.001), BSPH (30), Mn (10), $\mathrm{Zn}(3), \mathrm{Br}(10), \mathrm{Pb}(1), \mathrm{CVOL}(0.03), \mathrm{CEL}(0.2), \mathrm{NO}_{3}^{-}(0.1)$ and $\mathrm{HNO}_{3}(0.02)$.

were highest for the NNW direction. Pittsburgh, PA, is located $110 \mathrm{~km} \mathrm{NNW}$ of DCL and is most likely the dominant source area for those elements (Fig. 4).

\section{Regional signature comparison}

Rahn and Lowenthal (1985) have developed a regional tracer system in which they characterize air masses from five regions of North America by the ratios of concentrations of six tracer elements to that of Se. They assume the air is sufficiently well mixed within the regions, having dimensions of hundreds of kilometers, and the ranges for the ratios are narrow enough, that particles in the air emerging from each region can be identified by their trace element concentrations. In most areas the major portions of the six elements ( $\mathrm{V}, \mathrm{Mn}, \mathrm{Zn}, \mathrm{As}, \mathrm{In}$ and $\mathrm{Sb}$ ) and $\mathrm{Se}$ are contributed by anthropogenic air pollution sources. However substantial amounts of $\mathrm{V}$ and $\mathrm{Mn}$ are contributed by soil and other crustal materials, so Rahn and Lowenthal (RL) use 'non-crustal' portions of them, obtained by subtracting crustal contributions calculated from $\mathrm{Al}$ concentrations in each sample multiplied by the (V/Al) and ( $\mathrm{Mn} / \mathrm{Al})$ ratios of Mason's crustal abundance pattern (1966). As RL work mainly with $\mathrm{Hi}$-vol samples, which include particles up to $30 \mu \mathrm{m} \mathrm{dia}$. or more, their crustal corrections are often quite large.

To compare our results with the RL model, one cannot simply sort the samples according to back trajectory and see if the ratios vary as expected based on the origin of the air mass: as the DCL site is near the upper end of RL's Lower Midwest (LMW) region, most samples are expected to contain an LMW contribution, with perhaps contributions from other regions more distant on the trajectory. In fact $\mathrm{RL}$ obtained their LMW signature from measurements made at the Allegheny site (Fig. 4) during part of the same August 1983 period the DCL measurements were being made. Therefore instead we performed chemical mass balances (CMBs) to fit the observed concentrations of the seven elements (including $\mathrm{Se}$ ) of each sample by a linear combination of RLs signatures for each of the five regions. For $\mathrm{V}$ and $\mathrm{Mn}$ non-crustal portions of these elements in each ambient sample, calculated by RLs procedure, were used. As anticipated the crustal corrections were small, because of the fine particle nature of the samples. Even though In was poorly measured this element was included in the CMBs because of its importance in identifying the presence of the Southern Ontario (SONT) signature. Indium concentrations above the analytical detection limit $\left(0.003 \mathrm{ng} \mathrm{m}^{-3}\right)$ were measured for about a third of the samples. For the rest a constant value of half the detection limit was assumed, effectively defining a non-zero upper limit for the SONT contribution.

In the CMB procedure the concentration of element $i$ is given by:

$$
C_{i}=\sum_{j=1}^{5} m_{j} x_{i j}
$$

where $x_{i j}$ is the concentration of element $i$ in particles from region $j$, and $m_{j}$ is the strength of the signature from region $j$ in the sample, i.e. the 'regional coefficient' (because the signatures are normalized to Se $=1.00, m_{j}$ is the concentration of Se contributed from region $j$ ). The $m_{j}$ values for each sample were obtained from an effective-variance least-squares fit, which 
Table 4. Average regional coefficients of Rahn and Lowenthal tracer system vs wind sector of back trajectory

\begin{tabular}{|c|c|c|c|c|c|c|}
\hline $\begin{array}{l}\text { Wind } \\
\text { sect. }\end{array}$ & $\begin{array}{l}\text { No. } \\
\text { cases* }\end{array}$ & NENG & $\mathrm{CEC}$ & $\begin{array}{c}\text { Regional coefficients } \dagger \\
\text { LMW }\end{array}$ & UMW & SONT \\
\hline WSW & 23.1 & $<0.001$ & $0.01 \pm 0.03$ & $1.90 \pm 0.84$ & $0.02 \pm 0.06$ & $<0.003$ \\
\hline WNW & 27.5 & 0 & $0.01 \pm 0.03$ & $2.41 \pm 0.94$ & $0.04 \pm 0.11$ & $<0.002$ \\
\hline NNW & 27.0 & $<0.002$ & $0.005 \pm 0.018$ & $2.23 \pm 1.10$ & $0.31 \pm 0.40$ & $0.005 \pm 0.015$ \\
\hline NNE & 15.1 & $0.004 \pm 0.019$ & $0.023 \pm 0.022$ & $1.21 \pm 0.93$ & $0.17 \pm 0.22$ & $0.007 \pm 0.007$ \\
\hline ENE & 5.2 & 0 & $0.11 \pm 0.14$ & $1.00 \pm 0.81$ & $0.15 \pm 0.13$ & $0.008 \pm 0.006$ \\
\hline
\end{tabular}

* Non-integer because trajectories for many sampling periods were apportioned to more than one sector.

† Uncertainties are standard deviations of the coefficients for events falling within the sector.

takes account of the errors in both the observed concentrations and the regional signatures (Watson et al., 1984).

Results of the CMBs are summarized in Table 4, which lists the average regional coefficients for the 98 samples for which there were no missing values of Se or Al or any two other elements. As was done above, samples were assigned proportionally to more than one wind sector if the back-trajectory was not confined to a single sector, thus accounting for the nonintegral number of cases falling within each sector.

The LMW signature was present in all 98 samples, in 20 of them being the only non-negative contribution. Forty-seven samples had contributions from LMW and one other region, 14 from two other regions, 16 from three and only one sample had nonnegative strengths from all five regions. The CMBs involving regional signatures are different from those of an urban area, in which a half dozen or so source signatures are typically resolved from each sample's composition pattern. Rahn and Lowenthal (1985) indicated that most samples collected at Underhill, VT, and Narragansett, RI, have contributions from only one or two regions.

As expected, the LMW signature is the only significant contributor for back trajectories from the WSW. It is also strongly dominant for WNW. In part, this dominance may arise from the fact that coal-fired power plants of the Ohio River Valley are very strong sources in the LMW, so its signature is probably that of distant coal-fired plants with small contributions from other sources in that region. Thus, the many coal-fired plants in the WNW sector probably contribute particles at DCL whose trace element signature is dominant in all sectors, but with lower absolute strengths in the easterly sectors, where there is less coal combustion.

The Upper Midwest (UMW) signature is supposed to be associated with the lower Great Lakes region, including Chicago, Cleveland, Detroit, etc., which release particles from metals and manufacturing processes, as well as from coal combustion, motor vehicles, etc. The UMW signature is richer than LMW in all of the tracer species relative to $S e$, by ratios ranging from 4.5 to 6.5 , except for $\mathrm{Sb}$, for which it is richer by a facto of 2.9. The major surprise in Table 4 is the weakness of the UMW regional coefficient for the WNW sector, where it should be strongest. The UMW strength is somewhat greater in the NNW sector, but still far from dominant, and it is stronger in the easterly sectors than in WNW! Altogether there is very little evidence for a UMW impact at the DCL site.

As expected, higher ncr-V/Se ratios in samples associated with the ENE sector yield detectable contributions of the Central East Coast (CEC) signature, a region characterized by oil combustion. The New England (NENG) and Southern Ontario (SONT) coefficients are always quite small.

After determining the regional coefficients for each sample, RL apportion sulfate by first performing a regression of its concentration vs the regional coefficients. We performed a multiple linear regression of the $S$ concentrations vs the regional coefficients, obtaining only two significant, non-negative terms:

$$
\begin{aligned}
\mathrm{S}\left(\mathrm{ng} \mathrm{m}^{-3}\right)= & (3190 \pm 160)\left[m_{\mathrm{LMW}}\right] \\
& +(12,400 \pm 7300)\left[m_{\mathrm{CEC}}\right], r^{2}=0.39
\end{aligned}
$$

where the coefficients, 3190 and 12,400, are the S/Se ratios of particles from the $\mathrm{LMW}$ and CEC regions. Lowenthal and Rahn (1988) obtained corresponding ratios (after scaling $\mathrm{SO}_{4}^{2-}$ to S) for $\mathrm{LMW}$ of 2400 and 3500 for samples collected at Narragansett and Underhill, respectively, which bracket our value of 3190. As Tuncel et al. (1985) have noted, values of about 3000 are observed far from the sources, where much of the $\mathrm{SO}_{2}$ has converted to $\mathrm{SO}_{4}^{2-}$, but values around 1700 are more typical of areas near coal-fired plants, where most of the Se, but little of the $S$ from nearby sources, is borne by particles. Thus, we are surprised to find S/Se ratios for LMW at DCL as high as those observed much farther away by RL.

The S/Se ratios for CEC particles observed at Narragansett and Underhill (Lowenthal and Rahn, 1988) are 2500 and 7000 , respectively, vs our value of 12,400 . In this case, their samples are taken close to the region and ours more distant, so we expect to see a higher ratio, but its uncertainty is so large that one cannot draw strong conclusions.

Inserting the average $m_{\mathrm{LMw}}$ and $m_{\mathrm{CEC}}$ values in Equation (5), we find that the average $S$ concentrations contributed by the $L M W$ and CEC regions at the DCL site are 6.3 and $0.4 \mu \mathrm{g} \mathrm{m}^{-3}$, respectively. 


\section{Linear correlations}

Table 5 shows linear correlation coefficients of many of the species from Table 1. For 95 observations, a correlation greater than 0.26 is significant at the $1 \%$ confidence level. Any correlations below this value are omitted. The reduced number of cases compared with those used in Table 1 came from the decision to eliminate apparent outliers, arbitrarily defined as a parameter value different from its mean by at least a factor of ten. Thus a single case each for $\mathrm{V}$ and $\mathrm{Sb}$ was omitted. The omissions strongly affected eleven of the correlation coefficients associated with $\mathrm{Sb}$ (in all cases increasing them from the $0.07-0.17$ range to the 0.28-0.44 range) and three associated with $V(V-N N E$ increased from 0.11 to 0.40 , while $\mathrm{V}-\mathrm{Sc}$ decreased from 0.47 to 0 and V-ENE decreased from 0.58 to 0.40 ). The outlier cases were retained in Table 1 (but not in any of the other calculations in this article) since their effect on the means was generally within the uncertainties given in Table 1.

Table 5 is arranged so that parameters with mutually high correlations tend to occur as clusters near the diagonal. While a high correlation between two elements does not necessarily indicate a common source, we nevertheless feel that careful examination of a correlation table is a useful diagnostic exercise, comparable to that of a factor analysis.

Proceeding down the diagonal the highest correlations occur among $\mathrm{SO}_{2}, \mathrm{Se}, \mathrm{S}$ and fine mass, which are all related to coal-fired power plant emissions. The WNW wind sector is the only one that is correlated (weakly) with these elements. Figure 1 supports the WNW as a general source area for coal-fired power plant emissions. The extremely high correlation of $\mathbf{S}$ with fine mass $(r=0.99)$ is consistent with the earlier observation that $\mathbf{S}$, if present in the form of ammonium sulfate at the time of laboratory analysis, accounts for $67 \%$ of the fine particle mass. Since it was noted that the other major particulate species (organics and nitrates) can account for no more than an additional $7 \%$ of the fine mass, the extremely high correlation coefficient suggests that most of the mass which is not accounted for is likely to be water of hydration associated with particulate sulfate.

The substantial correlation of $S$ and $S e(0.70)$ is similar to that observed concurrently at the Allegheny Mountain and Laurel Hill sites for these elements in the fine fraction, 0.75 and 0.71 , respectively, for about forty cases at each site (Pierson, pers. comm., 1988). The histogram (not shown) of the DCL S/Se ratios was essentially unimodal, with a mean and standard deviation of $2800 \pm 1500$, as indicated above.

Unexpected are the substantial (for 95 cases) correlations of $\mathrm{Si}$ with $\mathrm{S}$ and fine mass $(0.61$ and 0.66$)$, and its moderate correlations with $\mathrm{SO}_{2}$ and $\mathrm{Se}(0.45$ and 0.42). Similar sized fine particle correlations of $\mathrm{Si}$ with $\mathrm{SO}_{4}^{2-}$, mass, $\mathrm{SO}_{2}$ and $\mathrm{Se}$ (approximately 0.60 for about 40 cases) were also found at each of the two Ford Research Laboratory sites operated concur- rently with the DCL site (Pierson, pers. comm., 1988). We speculate that the origin of the $\mathrm{Si}-\mathrm{S}$ correlation is coal fly ash. Mamane and Dzubay (1986) microscopically identified $11 \%$ of the particles from one DCL coarse particle sample as fly ash, but unfortunately did not report any such fine particle analysis.

The second major group of highly correlated parameters consists of $\mathrm{Zn}, \mathrm{Mn}, \mathrm{Fe}$ and $\mathrm{K}$, elements associated with industrial and related anthropogenic activities. Arsenic and $\mathrm{Pb}$ also have moderate correlations with this group of elements. Although $\mathrm{Pb}$ appears with this group, $\mathrm{Br}$ does not, indicating a source for $\mathrm{Pb}$ in addition to motor vehicles. The wind sector NNW is moderately correlated with $\mathrm{Zn}$ and $\mathrm{Mn}$, suggesting Pittsburgh, PA as a possible source area for this elemehtal group (Fig. 4).

Soil-related elements $\mathrm{K}, \mathrm{Ca}, \mathrm{Sc}$ and $\mathrm{Si}$ make up the third major grouping of mutually correlated parameters. Lanthanum is also very likely in this group on the bases of its substantial correlations and modest enrichment factors (Zoller et al., 1974) with respect to these elements. Using the crustal abundances of Mason (1966) the enrichment factors for La are about two relative to $\mathrm{K}$ and $\mathrm{Ca}$, and about five relative to $\mathrm{Sc}$ and Si. Sodium's highest correlation is with $\mathrm{La}$ and its enrichment factors relative to the previous five elements are in the range 0.7--2.

Bromine and $\mathrm{Pb}$ are well correlated, as expected, due to their assumed motor vehicle origin. Nitrogen oxides are correlated (weakly) only with these two elements.

The only correlation of $\mathrm{V}$ is with the ENE and NNE wind sectors. While this is consistent with the eastern and northeastern U.S. being a region of substantial oil-burning activity, there may be an additional local influence. From the Allegheny Mountain and the Laurel Hill data taken concurrently with the DCL measurements Pierson et al. (1989) observed greatly increased $\mathrm{V}$ concentrations $(10-100 \times)$ when the wind was from the southeast $\left(160^{\circ}\right.$ at Allegheny, $135^{\circ}$ at Laurel). The same observation was made at Allegheny in 1977 (Pierson et al., 1980). If the back trajectory for the high V case in the DCL set, previously omitted as an outlier, were taken together with Pierson's observations, triangulation defines an approximately $15 \mathrm{~km}$ long region lying between the Allegheny site and Cumberland, MD (Fig. 4). We have not, however, been able to identify a candidate $\mathrm{V}$ emission source in this area.

\section{SUMMARY AND CONCLUSIONS}

A 1 month intensive field study conducted near Deep Creek Lake in rural western Maryland resulted in a comprehensive high-quality set of fine particle, gaseous and meteorological data. Particulate $S$ in the assumed form of ammonium sulfate constituted $67 \%$ of the fine particie mass on average. Fine particle $S$ and mass tracked each other remarkably well over 


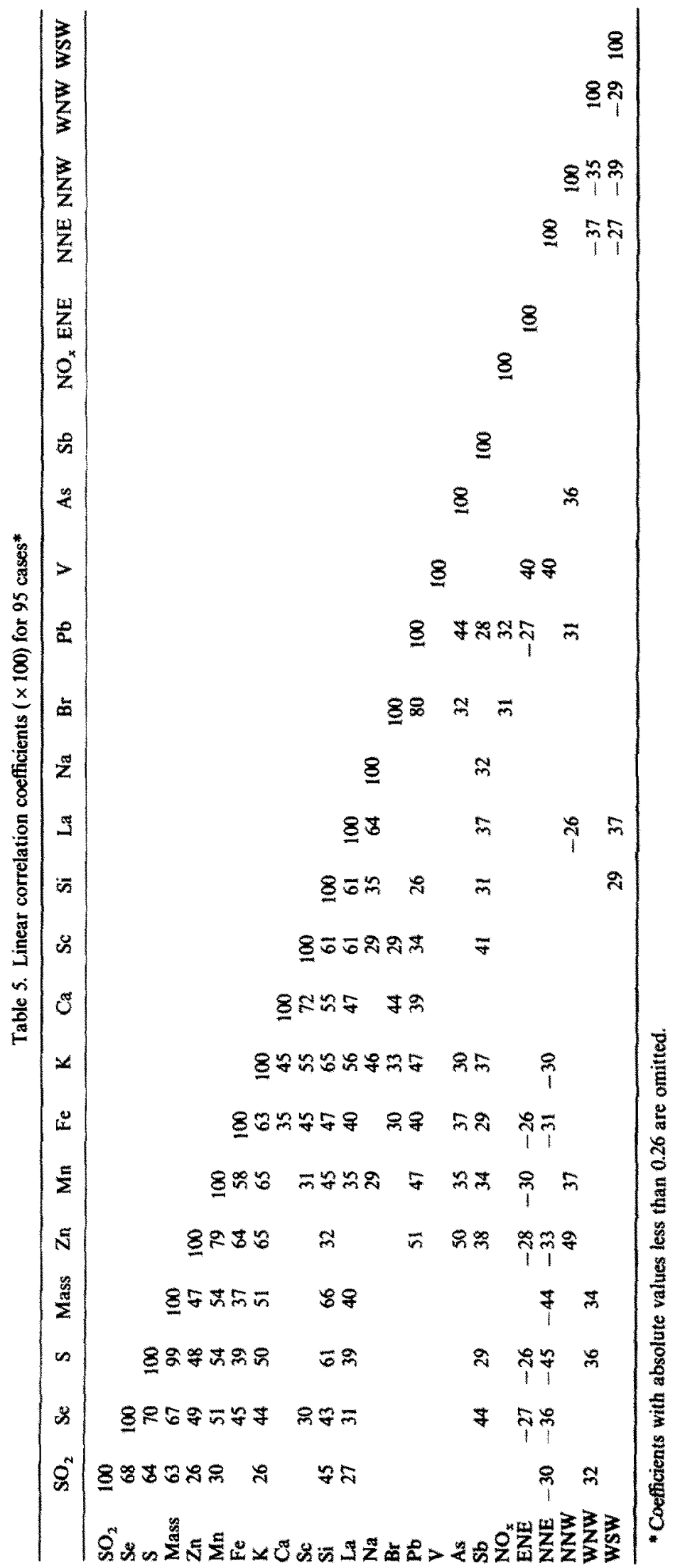


time $(r=0.99)$. The only other major particulate species $\left(\mathrm{NO}_{3}^{-}, \mathrm{CEL}, \mathrm{CVOL}\right)$ together can account for no more than $7 \%$ of the average fine particle mass, even when including the additional contributions of the cation associated with $\mathrm{NO}_{3}^{-}$(probably $\mathrm{NH}_{4}^{+}$) and the hydrogen and oxygen associated with volatilizable carbon. This fact, along with the very high correlation coefficient for fine particle $S$ and mass, in an indication of substantial water of hydration associated with particulate $\mathrm{SO}_{4}^{2-}$.

Sulfur dioxide expressed as $\mathbf{S}$ constituted more than half of the total $S$, indicating that the sampling site was being impacted by local sources.

Selenium, an element expected to come primarily from coal-fired power plants, followed the fine particle $S$ concentration over time fairly well $(r=0.70)$. The ratio of fine particle $S$ to Se was 2800 , characteristic of a rural site downwind of coal-burning areas (Tuncel $e t$ al, 1985).

Mixed-layer back trajectories were used to calculate wind frequency-normalized concentrations in each of eight wind sectors. Three of the sectors occurred with insignificant frequency and thus were not included in the results. Parameters associated with coal-burning ( $\mathrm{S}, \mathrm{Se}, \mathrm{SO}_{2}$, fine mass and $\mathrm{bsph}$ ) were highest for wind trajectories from the west-northwest where the greatest concentration of local and distant coal-burning power plants are located. Normalized concentrations of elements related to anthropogenic activity $(\mathrm{Mn}, \mathrm{Zn}, \mathrm{Br}$ and $\mathrm{Pb})$ were highest for wind trajectories passing through the Pittsburgh metropolitan area. Normalized concentrations of elements related to soil or fly ash ( $\mathrm{Si}, \mathrm{Ca}$ and $\mathrm{Fe}$ ) were highest in association with wind trajectories passing through less populated areas to the west-southwest. Vanadium was clearly associated with source areas to the northeast, where oil-burning power plants dominate. Parameters which behaved similarly with respect to wind direction were also mutually correlated

Use of Rahn and Lowenthal regional signatures showed an overwhelming dominance by the Lower Midwest region, and a surprisingly weak impact by the Upper Midwest region.

Any investigator may obtain our data on IBM-PC readable diskettes by sending two 360 kbyte diskettes or one 1.2 Mbyte diskette to one of the authors, $\mathrm{Dr}$ Charles W. Lewis.

Although the research described in this report has been funded by the United States Environmental Protection Agency, it has not been subjected to $\mathbf{A g}$ ency review and, therefore, does not necessarily reflect the views of the Agency, and no official endorsement should be inferred. Mention of commercial products does not constitute endorsement by U.S. EPA.

Acknowledgements-We express our appreciation to Dr William Courtney, Dr William Ellenson, Keith Kronmiller and Dr Charles Tipton for operating the instruments in the field, and Carolyn Owen for preparing the filters. We thank Dr M. Drew Ferrier for logistics support at the DCL site. We are indebted to Dr William Pierson for making available the back-trajectory calculations and for drawing attention to the vanadium phenomenon. We acknowledge the contribution of Dr Bernard Blaustein to the design of the study and the support by the U.S. Department of Energy of key contributors to this project. The Maryland group thanks Ann Sheffield, Dr Ithan Olmez, Dr Sally Harrison, Ming Han and Janet Joseph for their help. We thank the staff of the National Bureau of Standards nuclear reactor for their help with irradiations. The Maryland portion of the project was supported in part by Sandia National Laboratories under Contract No. 32-0959, the U.S. Environmental Protection Agency under PO No. 6D2560NAET and the State of Maryland Power Plant Research Program under Contract No. PR-88-107-004.

\section{REFERENCES}

Countess R. J., Wolff G. T. and Cadle S. H.(1980) The Denver winter aerosol: a comprehensive chemical characterization. J. Air Pollut. Control Ass. 30, 1194-1200.

Courtney W. J., Shaw R. W. and Dzubay T. G. (1982) Precision and accuracy of a $\beta$-gauge for aerosol mass determinations. Envir. Sci. Technol. 16, 236-239.

Dzubay T. G., Stevens R. K., Lewis C. W., Hern D. H. Courtney W. J., Tesch J. W. and Mason M. A. (1982) Visibility and aerosol composition in Houston, Texas. Envir. Sci. Technol. 16, 514-525.

Heffter S. L. (1980) Air Resources Laboratory's atmospheric transport and dispersion model. NOAA Technical Mem. orandum ERL ARL-81, National Oceanic and Atmospheric Administration Air Resources Laboratory, Silver Spring, Maryland, 1980.

Johnson R. L., Shah J. J., Cary R. A. and Huntzicker J. J. (1981) An automated thermal-optical method for the analysis of carbonaceous aerosol. In Atmospheric Aerosol Source/Air Quality Relationships (edited by Macias E. S. and Hopke P. K.), ACS Symposium Series 167, 223-233.

Koutrakis P. and Spengler J. D. (1987) Source apportionment of ambient particles in Steubenville, $\mathrm{OH}$ using specific rotation factor analysis. Atmospheric Environment 21, 1511-1519.

Lewis C. W., Baumgardner R. E., Stevens R. K. and Russwurm G. M. (1987) Receptor modeling study of Denver winter haze. Envir. Sci. Technol. 20, 1126-1136.

Loo B. W., Jaklevic J. M. and Goulding F. S. (1976) Dichotomous virtual impactors for large-scale monitoring of airborne particulate matter. In Fine particles: Aerosol Generation, Measurement, Sampling and Analysis (edited by Liu B. Y. H.), pp. 311-350. Academic Press, New York.

Lowenthal D. H. and Rahn K. A. (1988) Tests of regional tracers of pollution aerosols. 2. Sensitivity of signatures and apportionments to variations in operating parameters. Envir. Sci. Technol. 22, 420-426.

Mamane Y. and Dzubay T. G. (1986) Characteristics of individual particles at a rural site in the Eastern United States. J. Air Pollut. Control Ass. 36, 906-911.

Mason B. (1966) Principles of Geochemistry, third edn. John Wiley, New York.

Parekh P. P. and Husain L. (1982) Ambient sulfate concentrations and wind fow patterns at Whiteface Mountain, New York. Geophys. Res. Lett. 9, 79-82.

Pierson W. R., Brachaczek W. W., Truex T. J., Butler J. W. and Korniski T. J. (1980) Ambient sulfate measurements on Allegheny Mountain and the question of atmospheric sulfate in the northeastern United States. Ann. N.Y. Acad. Sci. 338, 145-173.

Pierson W. R., Brachaczek W. W., Gorse R. A. Jr., Japar S. M., Norbeck J. M. and Keeler G. J. (1987) Acid rain and atmospheric chemistry at Allegheny Mountain. Envir. Sci. Technol. 21, 679-691.

Pierson W. R., Brachaczek W. W., Gorse R. A. Ir., Japar S. M., Norbeck J. M. and Keeler G. J. (1989) Atmospheric 
acidity measurements on Allegheny Mountain and the origins of ambient acidity in the northeastern United States. Atmospheric Environment 23, 431-459.

Rahn K. A. and Lowenthal D. H. (1985) Pollution aerosol in the Northeast: Northeastern-Midwestern contributions. Science 228, 275-284.

Samson P. J. (1980) Trajectory analysis of summertime sulfate concentrations in the northeastern United States. J. appl. Met. 19, 1382-1394.

Shah J. J., Watson J. G., Cooper J. A. and Huntzicker J. J. (1984) Aerosol chemical composition and light scattering in Portland, Oregon: the role of carbon. Atmospheric Environment 18, 235-240.

Shaw R. W. Jr., Stevens R. K., Bowermaster J., Tesch J. W. and Tew E. (1982) Measurement of atmospheric nitrate and nitric acid: the denuder difference experiment. Atmospheric Environment 16, 845-853.
Stevens R. K. (1986) Modern methods to measure air pollutants. In Aerosols: Research, Risk Assessment and Control Strategies (edited by Lee S. D., Schneider T., Grant L. D. and Verkerk P. J.), pp. 69-95. Lewis Publishers, Chelsea, MI.

Tuncel S. G., Olmez I., Parrington J. R., Gordon G. E. and Stevens R. K. (1985) Composition of fine particle regional sulfate component in Shenandoah Valley. Envir. Sci. Technol. 19, 529-537.

Watson J. G., Cooper J. A. and Huntzicker J. J. (1984) The effective variance weighting for least squares calculations applied to the mass balance receptor model. Atmospheric Environment 18, 1347-1355.

Zoller W. H., Gladney E. S. and Duce R. A. (1974) Atmospheric concentrations and sources of trace elements at the South Pole. Science 183, 198-200. 